\title{
Proteins Immunologically Related to Neurospora Histidinol Dehydrogenase
}

\author{
By E. H. CREASER AND MARY GARDINER \\ Research School of Biological Sciences, Australian National University, \\ Canberra, A.C.T.
}

(Accepted for publication I I November 1968)

SUMMARY

\begin{abstract}
Antibody to pure Neurospora histidinol dehydrogenase has been prepared from rabbits. Extracts of Neurospora strains mutant at the his-3 locus have been examined by the double diffusion technique to ascertain whether or not they produce proteins which cross-react with this antibody. A total of 129 mutants, including 52 non-complementing ones, gave a positive reaction; no mutants have yet been observed which gave a negative result. In all cases two major precipitin bands were produced and it was shown that these corresponded to the $4 S$ and the $7 S$ forms of the enzyme. Dehydrogenation of histidinol by purified wild-type enzyme was completely inhibited by the antibody prepared against pure histidinol dehydrogenase and by antibody prepared against pure HD from the mutants K 445 and K959, which produce a modified HD enzyme. HD activity was also inhibited by antibody prepared against partially purified homologous protein from the two noncomplementing mutants $\mathrm{K} 492$ and $\mathrm{K} 474$. It was possible to reduce the efficiency of neutralisation of $\mathrm{HD}$ by antibody if this was treated with extracts of mutants $\mathrm{K} 492$ and $\mathrm{K} 474$.
\end{abstract}

\section{INTRODUCTION}

In Neurospora crassa the his-3 gene is responsible for the synthesis of a protein which has three enzymic functions; the most easily measured one is the dehydrogenation of histidine. This enzyme has been purified and partially characterized by Creaser, Bennett \& Drysdale (1967), and it became of interest to study the effect of amino acid substitutions due to mutation on its structure and activity. Certain mutants produce proteins which have activity and these enzymes can be purified and their properties investigated (Creaser, Bennett \& Drysdale, 1965, 1967, and Bennett \& Creaser, 1967), but the majority of mutations at this locus do not have histidinol dehydrogenase (HD) activity. It is likely that these represent more drastic changes in the protein structure which abolish enzymic activity. One way in which these inactive proteins can be purified and analysed is if they react with antiserum prepared against pure wild type HD. This paper reports an immunological survey of the proteins produced by his-3 mutants of Neurospora crassa.

Immunological studies have been performed on many enzymes (Cinader 1963) and two well studied Neurospora enzymes have been examined in this way. These are tryptophan synthetase (Suskind, 1957; Garrick \& Suskind, 1963) and glutamic dehydrogenase (Roberts \& Pateman, 1964 and Roberts, 1966, 1967) and in both cases proteins were detected which were not enzymically active but reacted with antisera to purified enzyme (CRM). 


\section{METHODS}

Organisms. Neurospora crassa strain EMERSON A and all the mutants prefixed $\mathrm{K}$ used in this work were provided by Professor D. G. Catcheside. Mutants prefixed M were obtained from Dr Mary Case of Yale. All mutants, except $\mathrm{K} 874$ which was isolated after $\mathrm{x}$ irradiation, had been obtained by $u . v$. radiation and selected by the filtration enrichment procedure of Catcheside (1954). Mutants were grown on Vogel minimal medium (Vogel, I955) containing $2 \%$ sucrose and $30 \mathrm{mg}$. L-histidine per litre with forced aeration. They were maintained in the same medium to which $\mathrm{I} \cdot 5 \%$ Ionagar had been added. The wild-type organism was grown on this medium without histidine.

Antibody production. 3-10 mg. of pure enzyme made according to the procedure of Creaser et al. (1967), normally in $0.05 \mathrm{M}$-phosphate buffer resulting from the last stage in purification, was emulsified with an equal volume of Freund complete adjuvant and injected intramuscularly into rabbits. When necessary subsequent injections were given by the same technique but using incomplete instead of complete adjuvant.

After 2 weeks the rabbits were bled by removing 20-30 ml. from the ear vein. This blood was allowed to clot in a test tube and the clot released from the side of the tube which was then left overnight in the refrigerator for the clot to contract. The serum was decanted and centrifuged to remove blood cells and stored frozen.

Double diffusion technique. Plates were poured with $0.0 \mathrm{I} \mathrm{M}$-phosphate buffer ( $\mathrm{pH}$ 6.8) containing I \% Ionagar. A circular mould was used 2 in. diameter and after the agar had set holes were cut with a cork borer to the patterns shown in the figures. For use the centre well was normally filled with antibody and the orbital wells with the material under test. The plates were then stored at $5^{\circ}$ for $48 \mathrm{hr}$ to permit precipitin bands to form.

Enzyme assays. Histidinol dehydrogenase activity was assayed by reduction of NAD at $340 \mathrm{~m} \mu$ using a Shimatzu recording spectrophotometer. To $0.1-0.5 \mathrm{ml}$. of enzyme preparation was added $0.2 \mathrm{ml}$. (2 $\mu$ mole) of NAD solution and tris/ $\mathrm{HCl}$ buffer, $0.05 \mathrm{M}$ ( $\mathrm{pH} \mathrm{9.}$ ) containing I mg. $/ \mathrm{ml}$. of 2-mercaptoethanol. After incubation of the spectrophotometer cuvette for $2 \mathrm{~min}$. at $34^{\circ}$ to permit temperature equilibration, $0.2 \mathrm{ml}$. $(0.4 \mu$ mole $)$ of histidinol solution was added and the increase in extinction at $340 \mathrm{~m} \mu$ was recorded.

\section{RESULTS}

Preparation of antigens and mutant extracts. Pure Neurospora histidinol dehydrogenase (NHD) was prepared according to the previously published procedure (Creaser et al. 1967). Pure enzyme was also prepared from mutants K 445 and K959 by this procedure-differing in that fractionation with ammonium sulphate was achieved with different percent saturations from those used in purifying the wild-type enzyme and the elution positions on the final chromatogram were slightly different. Less highly purified proteins were prepared from mutants $\mathrm{K} 492$ and $\mathrm{K} 474$ by following the published procedure, again modifying the ammonium sulphate fractionation step, to a point where NHD would be purified about roo-fold.

Crude extracts were prepared from the mutants by the following procedure. Mutants were grown in 81 . batches in Io 1 . bottles for 3 days at $25^{\circ}$ with aeration; about 15 g. dry wt/organism being produced per bottle. The Neurospora was harvested 
by filtration, lyophilized and stored at $-10^{\circ}$ until needed. The mutant powder was moistened with $0.05 \mathrm{M}$-tris buffer (pH 9.I) and ground with glass in a cooled mortar. After grinding the preparation was extracted with the same buffer and centrifuged at $20,000 \mathrm{~g}$ for $20 \mathrm{~min}$. to remove glass particles and mycelial debris. The supernatant was decanted and used without further treatment. It was found in earlier work that the yield of active NHD was enhanced by the inclusion of I $\mathrm{mg} . / \mathrm{ml}$. 2mercaptoethanol in the extraction buffer. However, when the ground mycelium was extracted with $\mathrm{pH} 9 \cdot \mathrm{I}$ buffer no differences were observed in the precipitin reactions whether mercaptoethanol had been present in the buffer or not.

Survey of antigen-antibody reactions in his-3 mutants. It was found that the serum taken from rabbits 2 to 10 weeks after they had been injected with NHD would precipitate and enzymically inactivate this antigen. Accordingly a survey was made of the reaction between this antiserum and crude extracts of the available his-3 mutants by the double diffusion technique as described. This survey was performed twice with two different batches of antiserum elicited by separate HD purifications. The results were the same in all cases in that all mutant extracts gave precipitin bands

\section{Table I. Neurospora histidine-3 mutants producing CRM}

\section{A. Non-complementing mutants}

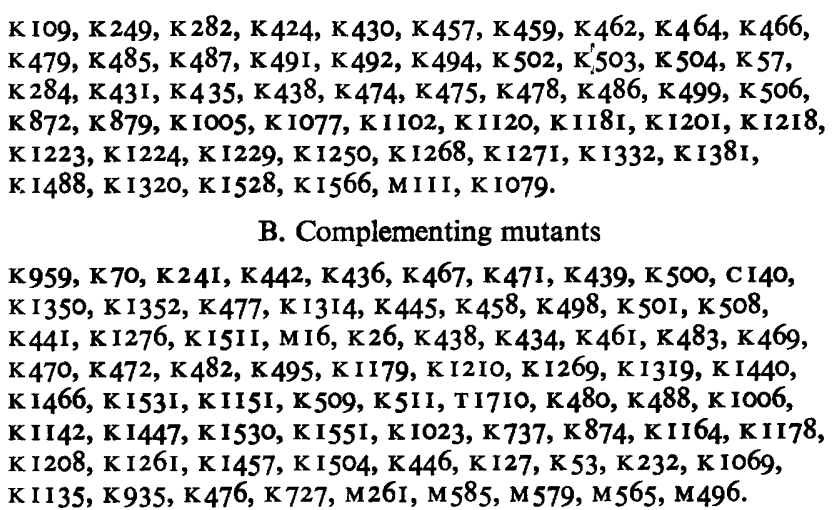

with antiserum to NHD. Table I lists these mutants and it can be seen that, of a total of 129 tested, 52 were non-complementing mutants. Figure I shows typical reactions between pure wild type HD and five mutant extracts. In all experiments in the survey each plate had one well with either crude extract of wild type or purified HD. Purified HD can exist either in the single molecular species or as a mixture of forms (see below). In Fig. I the pure HD used was the multiple species type. All mutants in this experiment give two bands, continuous with the two bands of the pure wild type HD and this result was obtained with all mutants listed in Table $\mathrm{I}$.

Multiplicity of Precipitin bands. It is known that NHD can exist in several polymeric forms-the two major forms being characterised by approximate sedimentation constants of $4 S$ and $7 S$ respectively (Creaser et al. 1967). Creaser et al. also showed that it was possible to prepare pure NHD in the single species $7 \mathrm{~S}$ form and as the mixture of $4 S+7 S$. Such preparations were made and tested against antiserum to pure NHD. The pure $7 \mathrm{~S}$ form was used as the antigen but the mixed $4 S+7 S$ gave identical results. Pure $7 \mathrm{~S}$ enzyme gave one major band, pure $4 S+7 S$ enzyme gave two 
major bands which correspond to those found in crude extracts of mutants and wild type (Fig. 2). Older preparations of $7 S$ NHD contained progressively more of the $4 S$ form as they age.

A different type of multiple banding occurred when samples of NHD lose enzyme activity on standing at $5^{\circ}$. As the sample became inactivated the single $7 S$ band split into several very close bands, possibly due to molecules in different states of oxidation.

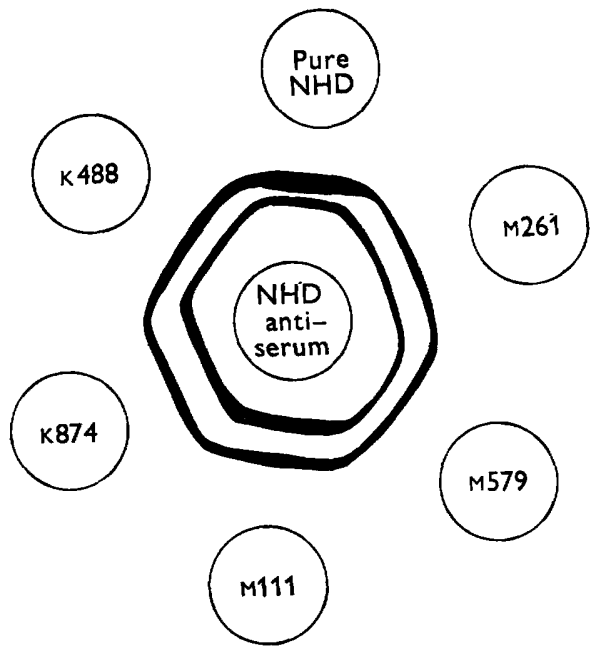

Fig. I

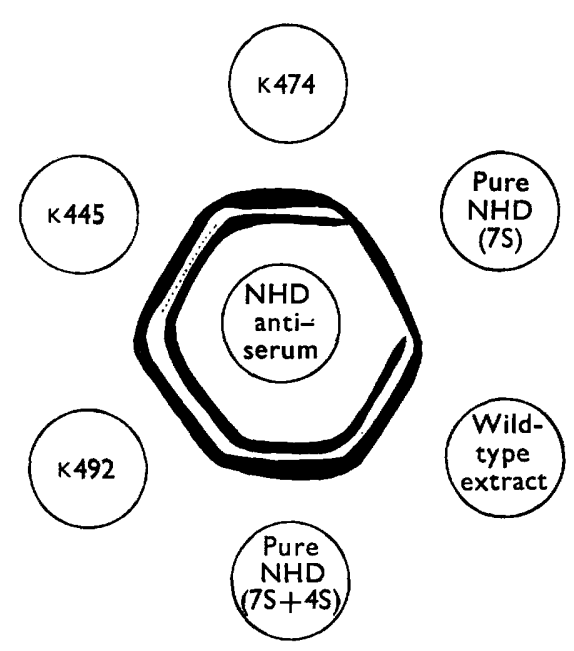

Fig. 2

Fig. I. Reaction between antiserum to wild type Neurospora histidinol dehydrogenase (NHD) (centre well), various crude extracts of his-3 mutants and pure NHD (peripheral wells).

Fig. 2. Reaction between anti NHD in centre well with pure NHD in the $7 S$ form and the $7 S+4 S$ form, crude extracts of wild type, two non-complementing mutants (K434, K492) and one complementing one (K445).

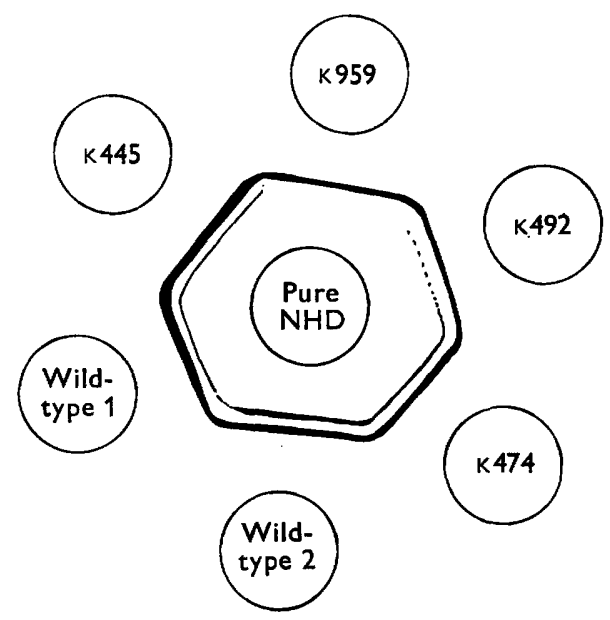

Fig. 3. Reactions between NHD and various antisera. Pure NHD in centre well with six antisera in peripheral wells. Antisera to pure NHD: two separate preparations of wild type, and preparations of K445, K595; antisera to partially purified K492 and K474. 
If an enzyme preparation, either the $7 S$ form or the mixed $4 S+7 S$, was converted to its monomeric condition all antigenic activity was lost. Enzyme sub-units can be prepared either by oxidation with performic acid (Moore 1963) or by reduction and carboxymethylation (Moore, Cole, Gundlach \& Stein 1958) but neither preparation gave precipitin bands when tested against anti-NHD serum.

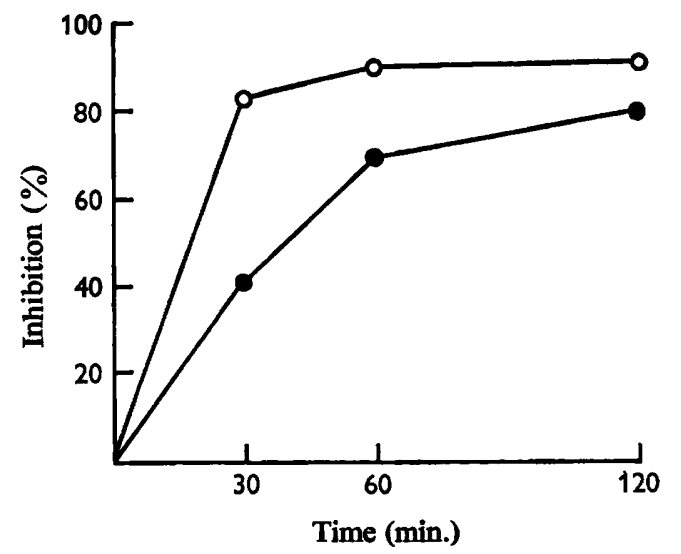

Fig. 4. Inhibition of NHD activity by $\mathrm{I} \cdot 0 \mathrm{ml}$. antiserum $\mathrm{O} \longrightarrow \mathrm{O} 0 . \mathrm{l} \mathrm{ml}$. antiserum $\bullet-$

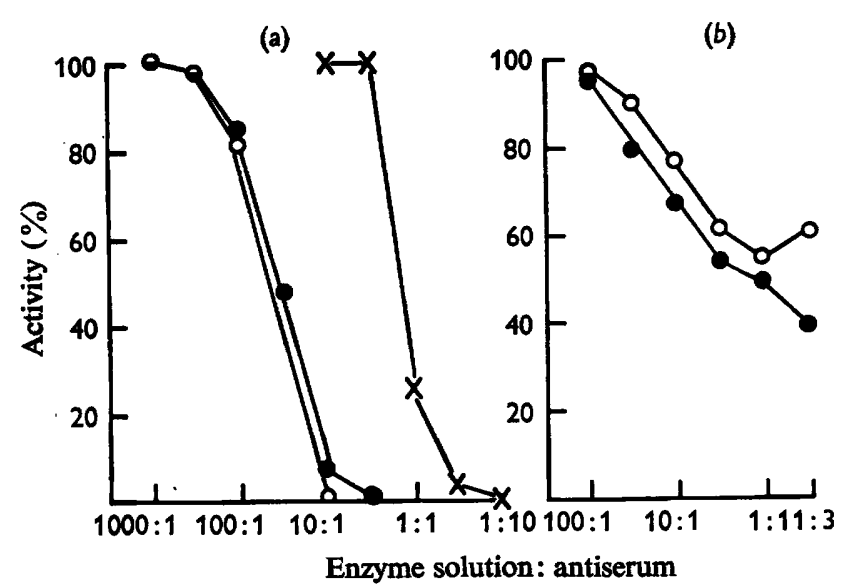

Fig. 5

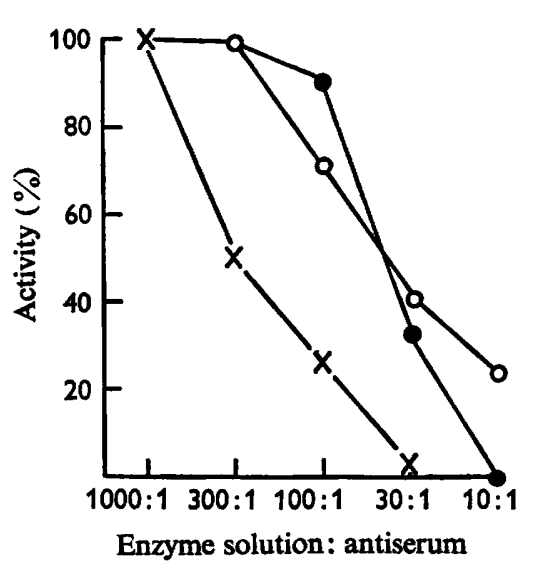

Fig. 6

Fig. 5. Inhibition of NHD activity by (a) Antiserum to pure enzymes; $\rightarrow$ wild type, $\mathrm{O}-\mathrm{O}$ K445, $\times-\times$ K959. (b) Antiserum to partially purified $\mathrm{O}-\mathrm{O}$ K492 and K474 enzymes.

Fig. 6. Protection by two non-complementing mutant extracts $0-0$ K492 and $\mathrm{K} 474$ of inhibition of NHD activity by antisera to pure NHD $\times-\times$.

Reactions of other antisera. Antisera were prepared to pure NHD from mutants K445 and K959 originally to investigate their reactions with mutant extracts which did not react with anti wild type NHD. In the event their production was superfluous but it was confirmed that both these antisera would react with wild type enzyme and also with a random selection of mutant extracts. In addition antisera were prepared 
against partly purified extracts of mutants K492, K474. These antisera although weaker than the antisera produced against pure enzymes would give precipitin bands. The reactions of various antisera against pure NHD are shown in Fig. 3.

Inhibition of enzyme activity by antisera. It was found that, as would be expected from the double diffusion experiments, histidinol dehydrogenase activity of either crude or pure NHD was inhibited by antiserum prepared against this enzyme. Preliminary experiments established the range for which inhibition occurred and Fig. 4 shows that the reaction was quite slow when the lower concentration of antibody was used. Normally, therefore, the reaction was allowed to proceed for $3 \mathrm{hr}$ at $37^{\circ}$. For this experiment $0.1 \mathrm{ml}$. of enzyme, normally about $25 \mu \mathrm{g}$, and with an activity of 0.05 i.u. $/ 0.1 \mathrm{ml}$. was incubated with $0.1 \mathrm{ml}$. of antibody of various dilutions. After incubation the sample was assayed for histidinol dehydrogenase activity as described above and the results were expressed as percentage of the activity of a similar sample incubated in the absence of antiserum. Figures $5 a$ and $5 b$ show the inhibition by five antisera. The antisera produced to the purified enzymes $(a)$ are more effective than those produced in response to injections of the partially purified homologous proteins $(b)$. Control sera taken from these rabbits before injecting the antigens did not inhibit HD activity.

Figure 6 shows that incorporation of extracts of $\mathrm{K} 474$ and $\mathrm{K} 492$ in the incubation mixture had a considerable effect in antagonizing the effect of anti NHD on the dehydrogenation reaction.

\section{DISCUSSION}

In view of the surprising result that all mutants tested, including the non-complementing ones, produced material which would cross react with anti-NHD serum it was thought advisable to check this observation by using antiserum to several mutants, especially non-complementing ones. The supporting evidence resulting, together with experiments on the effects of various antisera on dehydrogenation of histidinol by NHD and the protective effect of $\mathrm{K} 474$ and $\mathrm{K} 492$ extracts, makes it reasonably certain that all of the his- 3 mutants tested produced a protein which was sufficiently similar to NHD to give a cross-reaction.

These proteins must have some tertiary structure because monomeric units would not cross react; mutations giving rise to single amino acid changes-missense mutants -could produce such proteins. If one assumes that a considerable portion of the HD polypeptide is needed for polymerisation to occur then chain termination and frame shift mutations could only give rise to protein which is antigenically recognizable when the mutation was close to that end of the gene which was translated last. In this event all such mutations could not be distinguished antigenically from simple missense mutations.

The authors wish to thank Dr D. Jones and Mr D. Hardman for assistance with immunological procedures.

\section{REFERENCES}

BenNetT, D. J. \& Creaser, E. H. (1967). Amino acid substitutions in mutant forms of histidinol dehydrogenase from Neurospora crassa. Biochem. J. I05, 39.

CATCheside, D. G. (1954). Isolation of nutritional mutants of Neurospora crassa by filtration enrichment. J. gen. Microbiol. Ir, 34. 
Cinader, B. (1963). Introduction: Immunochemistry of enzymes. Ann. N.Y. Acad. Sci. 103, 495.

Creaser, E. H., BennetT, D. J. \& Drysdale, R. B. (1965). Mutant forms of histidinol dehydrogenase from Neurospora crassa. Can. J. Biochem. 43, 993.

Creaser, E. H., Bennett, D. J. \& Drysdale, R. B. (1967). The purification and properties of histidinol dehydrogenase from Neurospora crassa. Biochem. J. 103, 36.

GARRICK, M. D. \& SuSKIND, S. R. (1963). Antigenically active fragments of tryptophane synthetase. Ann. N.Y. Acad. Sci. I03, 793.

Moore, S. (1963). On the determination of cystine as cysteic acid. J. biol. Chem. 238, 235.

Moore, S., Cole, D. R., Gundlach, H. G. \& Sten, W. H. (1958). On the cleavage of disulfide bonds in proteins by reduction. Proc. IV. int. Congr. Biochem. 8, 52.

ROBERTS, D. B. (1966). Immunological and enzymatic studies on glutamic dehydrogenase and a related protein from Neurospora crassa. J. Bact. 9I, 1888.

RoBERTS, D. B. (1967). Immunological studies on glutamic dehydrogenase and two mutant forms of the protein. J. Bact. $94,958$.

Roberts, D. B. \& Pateman, J. A. (1964). Immunological studies of amination deficient strains of Neurospora crassa. J. gen. Microbiol. 34, 295.

Suskind, S. R. (1957). Properties of a protein antigenically related to tryptophane synthetase in Neurospora crassa. J. Bact. 74, 308.

VoGel, A. J. (1955). A convenient growth medium for Neurospora. Microb. Genet. Bull. I3, 42. 